\title{
UN SANTUARIO IBERORROMANO SAGUNTINO SITUADO EN LA MONTAÑA FRONTERA (SAGUNTO, VALENCIA)
}

$M^{a}$ Rosario NICOLAU VIVES

\section{Resumen}

En la cima de la Montaña Frontera se encuentra un yacimiento que por los restos materiales hallados en él, en su mayoría inscripciones latinas de carácter votivo, se ha determinado como un santuario, con un período de actividad que abarca la época iberorromana llegando hasta el Bajo Imperio.

\section{Summary}

In the top of the Montaña Frontera is located an archaeological site identified as a sanctuary. Most of their finds are iberian and latin inscriptions of votive character. Its period of activity undertakes from the Iberorroman period until the Low Empire.

\section{Introducción}

La intención de este artículo consiste en exponer las conclusiones a las que llegamos al finalizar la Tesis de Licenciatura (NICOLAU, 1997), que trató sobre el tema que se nos presenta en el título de este trabajo. Aprovechamos para agradecer a la Dra. Carmen Aranegui Gascó sus consejos y paciencia durante la elaboración del trabajo, así como a los demás miembros del tribunal que lo juzgaron, la Dra. Helena Bonet Rosado y Dr. Pere Pau Ripollés Alegre.

El yacimiento está emplazado en la cumbre de una montaña denominada Montaña Frontera, que se levanta a $378 \mathrm{~m}$. de altura sobre el nivel del mar y se sitúa en el término de Sagunto (Valencia) (Lám. 1).

Las primeras noticias relacionadas con los hallazgos pertenecientes a este emplazamiento se dan a comienzos del siglo XIX. Desde este momento hasta la fecha se sucederán diversas publicaciones que giran en torno a dos ejes principales, uno dedi- 
cado a elaborar una recopilación del material epigráfico y otro canalizado a explicar y verificar el yacimiento como un santuario dedicado al culto de Liber Pater y, anteriormente, a una divinidad indígena de época ibérica (NICOLAU, e. p.).

\section{El espacio sacralizado de la Montaña Frontera ¿Ibérico o Romano?}

\section{Características de la Montaña Frontera en época romana}

El yacimiento de la Montaña Frontera es un espacio sacralizado situado en un lugar alto donde existe una actividad cultual desde una época temprana para el mundo romano, siglo I a.C., y que continúa sin interrupción hasta el siglo II d.C. Su origen ibérico es difícil de determinar ante la falta de datos materiales que lo confirmen pero como veremos a continuación podríamos estar ante un lugar de culto de origen ibérico que se sincretizó en un culto de carácter romano.

Para el momento romano debemos conjugar varios puntos.

\section{Liber Pater: Origen y rasgos particulares}

El más importante, por el hecho de no plantear ninguna duda sobre su veracidad, es Liber Pater porque era, ciertamente, el dios adorado en este lugar, ya que encontramos numerosas inscripciones votivas con su nombre que lo confirman. Para determinar el carácter que pudo adquirir en la Montaña Frontera nos remitimos, necesariamente, a sus orígenes y características particulares y al observar la evolución de esta divinidad en el transcurso de los siglos, vemos que tuvo múltiples transformaciones y contradicciones.

Es una divinidad indígena itálica que surge a comienzos de la época romana, cuyo carácter y sentido primitivo se alteraron bajo la influencia de la mitología griega (TOUTAIN, 1900, 1189). Con el paso del tiempo se irá perfilando unas semejanzas y unas diferencias presentes en las provincias donde se extienda su culto (provincias danubianas y africanas, la Galia, Germania e Hispania) (BRUHL, 1953, I-II). Pero, originalmente, Liber es, realmente, original de las divinidades griegas (ROSE, 1976, 607; TOUTAIN, 1900, 1189).

Antes de adentrarnos en el estudio de Liber Pater se debe conocer al dios que le precede, Dionisos. Este dios se distingue por su aspecto cambiante, múltiple y diverso de su personalidad, de su mito y de su culto. Unos lo consideraban como un héroe divinizado y otros reconocían en él un dios. Su nombre no es siempre el mismo pues aunque es más frecuente el de Dionisos, también, se le llamó Baco. Para determinar los orígenes de su culto se han dado gran variedad de opiniones, una de ellas corresponde a Bruhl, quien consideró la personalidad del dios como producto de la fusión de diversos elementos (BRUHL, 1953, 1-3).

Su naturaleza y sus atribuciones son múltiples y complejas. Se le relaciona en primer lugar con el culto como dios-toro; en segundo lugar como dios de la vegeta- 
ción; en tercer lugar, y para los cultivadores, como dios de la fecundidad agrícola debiéndole a él el arte de cultivar la viña y los árboles frutales; y, en cuarto lugar, como divinidad funeraria (BRUHL, 1953, 3-5).

El carácter agrario de su culto se observa en los ritos festivos dados en su honor y, particularmente, en uno dirigido a favorecer las cosechas. Pero aunque en un principio sus atribuciones se extendían a toda la vegetación, pronto se centrará en el cultivo de la viña. En época clásica, él es el protector de las cepas y de sus frutos y, más tarde, el dios del vino. Los griegos lo invocaban en el tiempo de la vendimia haciendo fiestas en su honor.

Se le conoce unido a Demeter; la espiga, símbolo de ésta y el racimo, símbolo de Dionisos, figuraban, simbólicamente, la prosperidad agrícola. Parece ser que los griegos honraron en sus santuarios a Dionisos al mismo tiempo que a Demeter y Coré (BRUHL, 1953, 5).

La hiedra era la hoja sagrada de este dios, conservaba la simbología de la fe en él y era un signo de reconocimiento entre los iniciados. Para formar parte de sus orgías había que someterse a una iniciación, existiendo una separación total entre iniciados y no iniciados. La participación en sus ceremonias orgiásticas creó entre sus seguidores un lazo místico y poderoso que fue formando las asociaciones que se encargaban no sólo de mantener el culto a este dios sino también de propagarlo (BRUHL, 1953, 8-9).

De Liber Pater no se conoce apenas más que el nombre; se le llama Liber o Liber Pater. Las formas más antiguas de la palabra Liber fueron Loebasius o Loebesus, Leiber y Leber (TOUTAIN, 1900, 1189). Los romanos del último siglo de la República no conocían con certeza el sentido ni la etimología de la palabra Liber; esta incertidumbre indica la gran antigüedad del culto de este dios en Italia. Se relaciona la palabra Liber a la raíz indoeuropea * lib, de donde se derivan las palabras como libare. Liber o Liber Pater era el dios que da, que versa en la abundancia y en la fecundidad (TOUTAIN, 1900, 1189).

Los orígenes de Liber Pater se remontan a los tiempos primitivos del mundo romano. Bruhl sostiene que los pobladores del Lacio tenían en su panteón un dios llamado Liber cuyo parecido con el Dionisos heleno venía determinado por tener un origen común y antiguo. Ambos eran dioses de la fecundidad y de la vegetación. Parece ser que en el Lacio, lo que hubo fue una especie de religión báquica indígena alrededor de Liber y Libera (GRIMAL, 1984, 318) y, concretamente, Lavinium fue uno de los centros principales de culto porque se sabe que había un mes consagrado a estas divinidades. Esto era un culto primitivo indígena dedicado a unos dioses campesinos protectores de las cosechas, a los cuales se les dedicaban unas fiestas con ritos naturalistas. Se celebraban las Liberalia cuando el trabajo de la tierra iba a comenzar, siendo esta fiesta genuina del Liber Pater itálico. Esta fecha excluye toda relación entre el Liber Pater romano y las vendimias. No 
es un dios de la viña sino un dios que presidía la fertilidad de los campos. Las Liberalia tenían un carácter fálico pero no estaban en relación con las faloforías griegas porque éstas se vinculaban directamente con la vendimia y la fabricación del vino y las itálicas no. El falo era el símbolo de Liber Pater siendo éste un dios de la fecundidad, protector de la fertilidad agrícola y, quizá, animal. Este carácter propio de Liber es lo que permite comprender su primera asimilación a una divinidad griega. A comienzos de la República romana se instituye en Roma el culto a la tríada Ceres, Liber y Libera que se corresponden con Demeter, Dionisos-Baco y Coré, respectivamente, cuyo culto era agrario. Posteriormente, Liber Pater se asimilará con Dionisos-Baco, no tardando el primero en convertirse para los romanos en el dios de la viña. Liber Pater supone una ruralización de un aspecto religioso en origen propio de Dionisos. Los viñadores adoraban a Liber al mismo tiempo que a Libera durante la vendimia, además, asociaban su culto a los de Silvano y Hércules, protectores de los campos, y los vendedores de vino unían sus invocaciones de Liber a Mercurio, dios del comercio (TOUTAIN, 1900, 1189-1190).

El atributo Pater, aunque en ocasiones aparece junto con otros dioses, estaba especialmente ligado a Liber y hasta el final del paganismo se invocará a Liber Pater (BRUHL, 1953, 13-14, 27-29).

No se conoce ninguna representación del Liber Pater propiamente itálico o romano porque siempre se mostró al Dionisos griego para este cometido (TOUTAIN, 1900, 1191). Las imágenes de Baco que se conservan en toda la periferia occidental (Africa del Norte, Galia, Germania, Lusitania, Hispania, etc.) son casi totalmente de época romana (HATT, 1991). La imagen del dios griego no aparece más que raramente y su fecha es difícil de fijar. El nombre de Baco y no el de Dionisos, es el que aparece en los textos literarios latinos; en cambio, el dios mencionado en las inscripciones y dedicatorias es Liber o Liber Pater (BOUCHER, 1988, 908, 921).

\section{Liber Pater: Carácter en la Montaña Frontera. Testimonios que lo avalan}

Liber Pater adquiere diferentes caracteres según el lugar donde se le rinda culto. Como ya hemos mencionado su culto se extenderá a las provincias danubianas, Panonia y Dacia, a Africa del Norte, a la Galia, a Germania y a Hispania. Bruhl sólo conoce siete textos epigráficos referentes a la religión báquica situados en la parte occidental del país, lo que le llevó a pensar que el culto a Liber Pater no era muy popular en Hispania y que éste no era otro que el dios aportado por los colonizadores romanos (BRUHL, 1953, 212, 239-240).

En un estudio realizado veinte años después por A.M. Vázquez Hoys aumenta el número de inscripciones a Liber Pater en dos, siete de la Tarraconense (Cástulo, Carthago Nova, Castellar de Santisteban, Puzol, Barco de Valdeorras, Asturica y Tricio) y dos de Lusitania (Olisipo y Caurium), siendo dudosas dos de ellas. El número de fuentes as- 
ciende a ochenta y cuatro repartiéndose así: Fuentes epigráficas: nueve, fuentes arqueológicas, setenta y cuatro y fuentes numismáticas, una. Por provincias estaría repartido del siguiente modo: En la Bética, treinta y dos arqueológicas y una numismática, en Lusitania, dos epigráficas y doce arqueológicas y en la Tarraconense, siete epigráficas y treinta y ocho arqueológicas. Liber Pater sería la tercera divinidad adorada en Hispania, detrás de Júpiter y Diana, por el número de fuentes y décimo quinta según la epigrafía (VAZQUEZ HOYS, 1982, 439-442, 487-488, 709). Es decir, considerando sólo las inscripciones percibe al dios como una de las divinidades menos importantes de Hispania y no se atreve a fechar su culto en este lugar. Esta investigadora, tampoco conoce las de la Montaña Frontera, lugar donde se concentran un número de epígrafes dedicados a Liber Pater superando con creces el total de las que la autora recoge.

Sobre el carácter que adquiere este dios en Hispania se han dado opiniones contradictorias por el hecho de no conocerse todas las fuentes que han aparecido relacionadas con él. Por un lado, Bruhl consideró que el carácter de Liber Pater en Hispania era el aportado por los colonizadores romanos porque no fue muy popular. Igualmente, Vázquez Hoys (VAZQUEZ HOYS, 1982) no lo consideró de este mismo modo por los escasos restos referidos a él e, incluso, dijo que no hubo culto a Liber sino que la figura de Dionisos coincidía con la tradición romana siendo el motivo de que se desarrollara en época romana e, incluso, afirmó que no hubo un culto a Liber sino que la figura de Dionisos al coincidir con la tradición local se desarrolla en época romana. Para Mangas (MANGAS, 1978, 624-625), Liber Pater sería un dios asimilado del Dionisos griego, que recibe toda su mitología, y que tuvo mucha aceptación en ciudades muy romanizadas. Lo considera como un dios del vino importado y que no se asimiló con dioses indígenas al no ser aceptado entre las poblaciones que conservaban sus antiguas tradiciones religiosas pero sí por los ciudadanos romanos. Contrariamente, J. Arce (ARCE, 1986, 173: GARCIA SANZ, 1991-92) concibe a Liber Pater bien aceptado y difundido en Hispania.

Estos estudios y otros más (REDONDO, 1987-88, 52; 1988, 239), concentran el culto a Liber Pater en el área sur, noroccidental y centro oriental de la península, cuando los testimonios epigráficos de la Montaña Frontera superan a todos los reunidos hasta ese momento. J. Redondo, que no conoce los epígrafes de la Montaña Frontera, identifica un Liber Pater con las características del Dionisos griego porque cuando se venera en Hispania ya hacía mucho tiempo que había perdido su carácter original (REDONDO, 1988, 239).

Otra línea de interpretación viene dada por J. del Hoyo quien considera que el estudio del carácter de Liber Pater se debe hacer por provincias porque, y esto es lo importante, ha habido corrientes sincréticas que han asimilado al Liber Pater itálico con el Dionisos griego y con el dios indígena al que se venera en cada lugar, dando 
como resultado un dios particular en cada región. Él conoce las inscripciones de la Montaña Frontera y, junto con alguna más que había aparecido en otros lugares desde el estudio de Vázquez Hoys, menciona treinta y ocho en toda Hispania. Además, este investigador intenta vincular el culto a Liber Pater con el vino para encontrar el sentido de las inscripciones votivas, pero le falta un reconocimiento explícito para poder asegurarlo con certeza (DEL HOYO, 1988, 102-103, 115-118).

Y centrándonos en el carácter del dios en la Montaña Frontera, la opinión de Corell (CORELL, 1988, 141; DEL HOYO, 1992, 89) transcurre por otra vía asegurando que el dios de la Montaña Frontera estaría más cerca del Liber itálico, dios de los campos y la naturaleza, que del Dionisos griego, deidad del vino porque se dan una serie de rasgos que lo hacen así: los nombres de los dedicantes latinos, los gastos con dinero público, la existencia anterior de un dios ibérico, la mala calidad de las dedicatorias y su difícil vinculación con el vino. Para García Sanz (GARCIA SANZ, 1991, 189) es un dios popular con un culto comunitario a modo de patronazgo.

En resumen, por lo que podemos observar se ha hecho difícil determinar el verdadero carácter que tomó Liber Pater en Hispania y, en concreto, en la Montaña Frontera.

Una vía para el reconocimiento de su carácter en este santuario podría establecerse quizá a partir del sentido que recibió la divinidad que le debía preceder en este lugar pero, como ya apuntamos, la falta de datos para la época ibérica es un hecho, obligándonos a manejar, como ahora veremos, otros aspectos no menos importantes.

La situación destacada del santuario en lo alto de una montaña (el lugar alto conlleva un concepto religioso en la Antiguiedad (TARRADELL, 1979, 36) dominando todo un territorio, junto con el hecho de dedicar a Liber Pater un santuario en altura dentro del territorio saguntino en vez de un templo en la ciudad, lo acerca a un carácter agrícola. Esta idea vendría reforzada por el hecho de que este dios en su origen es el dios de la fecundidad, protector de la fertilidad agrícola y con el tiempo se convierte para los romanos en el dios protector de la viña (TOUTAIN, 1900, 1189-1190).

Junto con esto contamos con testimonios arqueológicos que no sólo avalan su carácter agrícola sino que lo consideran como un dios relacionado con la actividad vinícola.

En primer lugar, encontramos fragmentos de ánforas vinarias PE-16, Dr. 1A y B., Lamb. 2 y Dr. 2-4 saguntinas. De PE-16 sólo obtenemos un fragmento de boca que lleva la cronología hasta los siglos III-II a.C. El grupo de Dr. 1 lo forman cuatro fragmentos, parte de dos bocas Dr. 1A y un galbo y un asa Dr. 1B. Tan sólo contamos con el asa de una Lamb. 2, siendo tres, dos trozos de boca con parte del galbo y parte de un hombro, los fragmentos de las Dr. 2-4 saguntinas. 
Las ánforas Dr. 1 están relacionadas con el transporte de vino itálico y es uno de los materiales clave en Saguntum desde un momento temprano de la época republicana, de tal modo que llegan a ser las importaciones más representativas del momento, desapareciendo en los últimos decenios del siglo I a.C. El otro tipo de ánfora vinaria que da servicio en época republicana es la Lamb. 2. Su desaparición parece contemporánea a la de las Dr. 1, es decir, últimos decenios del siglo I a.C. El inicio de fabricación de las Dr. 2-4 saguntinas coincide con una época, siglo I d.C. y primera mitad del II d.C., donde en Sagunto se produce un auge del cultivo de la vid llegando a su máximo desarrollo. Este argumento está apoyado, por una parte, por la marca $G E M$, que hace referencia a la Gens Gemina y que, por la abreviación de los nomina, parece de esta época y que, por tanto, «sugiere la existencia de un negotiator saguntino en esta fecha» (ARANEGUI, 1991a, 49-52). Y, por otra parte, por los textos de la correspondencia de Plinio el Joven con su amigo Voconivs Romanvs que aparece nombrado en las inscripciones encontradas en Sagunto (CIL 2, 3.865 y 3.866) y la mención, por la misma época, de Juvenal sobre los vinos saguntinos (ARANEGUI, 1991a, 49-52; ARANEGUI-MANTILLA, 1987, 100-104). Esta fecha también coincidirá con las ofrendas epigráficas latinas de la Montaña Frontera.

En segundo lugar, este yacimiento nos ofrece restos de dolia importados, algunos de ellos con márcas, lo que apoyaría el carácter agrícola del lugar. El conjunto lo forman ocho fragmentos, dos de ellos son parte de la boca y el resto conservan las marcas:

1- Dos fragmentos en donde se lee la inscripción ...]Q. FA[... (ROCA, 1988, 81; MANGAS, 1990, 208, 723). Las letras miden $3 \mathrm{~mm}$. de espesor y su altura ronda entre los 6-7 cms. Un tercer fragmento, hoy en lugar desconocido, completaría la lectura pudiéndose leer Q. Fabivs [---]: Quintvs Fabivs (CORELL, 1988, 126, 11) (Lám. 2, nº 1).

2- Un sólo fragmento de galbo cercano al cuello muy mal conservado. En él se puede leer ...]V V S[... aunque con dudas pues todos los signos están cortados por la parte superior. La que parece una $\mathrm{S}$, aunque no entera, es la letra conservada más larga, midiendo $6,4 \mathrm{~cm}$. de altura (Lám. 2, $\mathrm{n}^{\circ} 2$ ).

3-Fragmento de galbo mal conservado con unas letras o signos ilegibles. Lo que se puede advertir es algo parecido a esto: ...]X I I[..., que podría corresponder a una cifra relacionada con la capacidad. Las medidas del fragmento son: Alto: 10,5 cm.; Largo: 14,8 cm.; Ancho: 2,7 cm. (Lám. 3, nº 3).

4- Fragmento que coincide con el hueco de una placa de plomo colocado por alguna rotura. En él se lee la letra ...]S[...; su altura es de 2,2 cm. (Lám. 3, n 4).

5- Para terminar, un fragmento de «asa de dolium» (SILGO, 1989, 18, 48; 1992, 361 , XLVIII) que lleva un grafito inciso antes de la cocción grabado con un instru- 
mento de punta roma. Se lee ...]GITAU[.... El segundo signo se ha interpretado también como una posible $C A$ mal hecha.

Son vasijas que se dan desde época republicana hasta el Bajo Imperio y desde finales del I a.C. e inicios del I d.C. comienzan a ser empleados para hacer fermentar el vino, aunque son vasijas de usos diversos conocidas desde tiempos más antiguos (MAU, 1979, 1285-1286). En Sagunto, los dolia también se emplearon para elaborar el vino en las «villae o centros de explotación» (ARANEGUI, 1990, 14).

En tercer lugar, contamos con una gran cantidad de inscripciones votivas sobre pedestales, con uno o dos agujeros en la superficie, aras y arulas, con decoración moldurada en algún caso, dedicadas a Liber Pater que relacionan el carácter agrícola con una función religiosa en el santuario. Algunas se conocen desde el siglo XIX gracias a los dibujos que hizo el cronista B. Ribelles en uno de sus trabajos (RIBELLES; RIBELLES a); entre ellas se encuentra la inscripción que ofrece una datación más antigua (siglo I a.C.) (Lám. 4).

Están datadas, sobre todo, en el siglo I d.C. y, también, primera mitad del II d.C.: se trata de cuarenta y seis inscripciones o parte de ellas inscritas sobre piedra caliza dolomítica azul, propia del lugar, exceptuando dos sobre mármol blanco.

El ara es el soporte para las inscripciones votivas más abundante en el territorio valenciano en época romana (CEBRIAN, 1993, 145). Las arulae pertenecerían a un culto personal. El pedestal tiene un carácter sacro por medio del cual se ofrece una estatua aunque en época romana es empleado, también, como objeto decorativo pero con una referencia religiosa. Las demás formas de soporte que aparecen, dos placas y un bloque bien pueden considerarse como otro tipo de ofrenda religiosa pero con el mismo sentido que las aras y los pedestales (GARCIA SANZ, 1991, 185-186).

Las letras y, en general, toda la pieza se conservan en mal estado pero sí se advierte que unas están mejor labradas que otras. Una de ellas sobresale por tener unas letras muy claras y una ejecución muy cuidada (Lám. 6).

El nombre del dios aparece con toda seguridad en seis ocasiones; en éstas, el nombre del dios está escrito siempre en dativo, se lee Libero Patri, Libero y Libero abreviado con una $L$ o con $L I$. Se sitúa tanto delante del dedicante como detrás de él o incluso sólo.

La fórmula votiva no siempre aparece aunque la mayor parte de las veces se piensa que es por estar fragmentadas. La fórmula más repetida es $V$. S. L. M., en cambio $V$. $S$. $L$ aparece sólo una vez. Otras fórmulas votivas son: faciendvm cvravervnt, ex voto y la $V$ de votvm. S.A.L.M. o pro salvte, aparece una sola vez. 
El hecho de que en los lugares hispanos donde han aparecido dedicatorias a Liber Pater predomine la fórmula votiva Sacrum y junto a ésta, otras como In/Ob Honorem, D.D., D.S.P.D.D., Fecit y, contrariamente, en la Montaña Frontera lo que predomine sea V.S.L.M. se ha considerado esta última bien como, fórmula propia de pedestales y aras cuyo destino era ser colocadas en un templo o bien como, término que gozaba de una mayor intención religiosa que Sacrum (GARCIA SANZ, 1991, 185-186).

Algún investigador no admite que muchas de estas inscripciones se relacionen con el culto a Liber Pater porque no aparece su nombre. Se considera lógica esta relación pero no es determinante para admitir que la promesa se dirija a este dios (GARCIA SANZ, 1991, 177-178). La mayoría cree que ocurre lo mismo que en otros santuarios donde, en ocasiones, en las ofrendas epigráficas no aparece el nombre del dios porque se sobreentiende que es a él; siempre se toma como ejemplo el santuario dedicado a Liber Pater en Sarmizegutsa (Dacia) donde el nombre de la divinidad no aparece en todas las aras pero sí se consideraron dedicadas a Liber porque éstas bien pudieron colocarse dentro del santuario quedando claro que habían sido ofrendadas a este dios (CORELL, 1988, 139; DEL HOYO, 1988, 104). Pero este razonamiento tampoco convence a este autor porque en Dacia sabe que eran aras y de la Montaña Frontera comenta que son lascas considerando «mudos o devaluados» varios epígrafes donde sólo está el nombre del dedicante (GARCIA SANZ, 1991, 177). Esto no es así, hay lascas pero la mayor parte de las ofrendas con epigrafía conservan su forma de ara o pedestal aunque estén fragmentadas y tampoco son mudos porque se lee el nombre del dedicante o la fórmula votiva en alguno de ellos. Entonces, en la Montaña Frontera ocurriría quizá algo similar a lo de este santuario porque, aunque no se tiene la certeza de la existencia de un templo, las gentes que acudían al lugar sí sabrían que ese lugar estaba consagrado a Liber Pater.

Los dedicantes aparecen en la mayoría de los fragmentos. En un caso están los nombres de dos dedicantes, cuyo cargo social se conoce sólo en ésta, son dos duumviros, en cambio, en las demás sólo hay uno:

[Lib]ero Patri/[.F]abivs Felix/[.F]abivs Fabianv[s/I]I viri ex d(ecreto) d(ecvrionvm)/ [pe]cvn(ia) pvbli[ca/f]aciend(vm) cv[ra/v]ervn[t] (BELTRAN, 1980, 256, 308) (vid. lám. 4, $\mathrm{n}^{\mathrm{o}} 1$ ).

Los nombres de los demás dedicantes son:

C(aivs). Lici(nivs). Cras(vs) (vid. lám. 4, no 3)

[Ba]ebia (vid. lám. 4, $\mathrm{n}^{\circ}$ 2)

---]cili[--- (vid. lám. 4, no 4)

M(arcvs). C[o]rneli/vs. Svpers[tes] 
$[$ Te]renti/[v]s Axsio/cvs.

Cn(aevs). Mal(---)/Florvs

$[--\mathrm{H}]$ erennia $[---]$

$\mathrm{Q}$ (vintvs). D(---).[---]

[.] Val(erivs)./[Se]ver(vs)

$\mathrm{Phr}$ [onimvs] o Thr[asyllvs]

[---] l(ivs). Ivcvndvs

Cn(aevs). I[---] (ó L[---]

Todos ostentan una condición libre menos dos libertos: un hombre y una mujer:

1.-----/L(ibertvs) Thr[--- (?) pro]/sal[vte---]/------?(ALFÖLDY, 1995, 128).

2.[Ba]ebia $\mathrm{Cn}$ (aei) 1(iberta)/[Gr]aeca/[v(otvm)] s(olvit) l(ibens) m(erito)

(ALFÖLDY, 1977, 35, 54) (vid. lám. 4, nº 2).

Este hombre liberto posee un cognomen de origen griego; junto con éste, hay otro que también lo ostenta griego pero es libre:

[Te]renti/[v]s Axsio/cvs. Libe/ro. V(otum). S(olvit). L(ibens). /M(erito) (CORELL, 1988, 132).

Además de la mujer liberta encontramos otra mujer, en este caso, también, de condición libre:

[---H]erennia [---]/[---] Venici [---]/[---] V+ [---]/------?(MANGAS, 1993, 154).

Todos los hombres llevan tria nomina siendo todos los gentilicios conocidos en la zona saguntina menos uno que aparece por primera vez: Herennia. Ningún nombre es ibérico pero según Corell sólo hay tres nombres ibéricos entre todas las inscripciones saguntinas (debieron romanizar su nombre pronto) (CORELL, 1988, 139-140).

En un sólo caso sabemos de donde procedía el dinero que se empleó para hacer la ofrenda (vid. lám. $4, \mathrm{n}^{\circ} 1$ ): se trataba del dinero municipal; con este dato, el yacimiento adquiere un carácter propio como centro de culto de gran arraigo entre la población autóctona.

De las inscripciones que han podido ser datadas con seguridad podemos decir que la más antigua se fecha a finales del siglo I a.C. y la más moderna en el siglo II d.C. Todas las demás se pueden separar en dos grupos, uno incluye las inscripciones seguras del siglo I d.C. y el otro las que pueden ser del I d. C. o II d.C. El resto no tienen determinada una cronología al estar muy fragmentadas o ser ilegibles.

En cuarto lugar, debemos señalar que la continuidad del yacimiento desde época Iberorromana hasta el período Bajo Imperial, viene apoyado por otros materiales, 
tanto cerámicos, minúsculos fragmentos de Campaniense A y B y Terra Sigillata Itálica, Gálica e Hispánica (el único fragmento datable de T.S.H. es del siglo III d.C.) como pétreos, pedestales, aras y arulas anepigráficos, bien por estar fragmentados y las letras se han perdido, bien por ser realmente así (Lám. 5, fig. 1). Junto con ellos, conocemos bloques indeterminados, fragmentos con restos de estuco, una parte de varios tambores de columna, un capitel jónico (Lám. 5, fig. 2) de piedra caliza dolomítica gris que conserva en cada pulvini una voluta muy deteriorada (la presencia de un capitel jónico en la Montaña Frontera es extraordinaria debido a que el número de capiteles de este estilo conocidos de Sagunto es muy escaso, siéndolo también lo que se ha dicho sobre ellos (CHINER, 1990, 16-18, 21, 78-81), una piedra de molino, un fragmento de mármol blanco correspondiente a la parte de una mano y una muñeca, un trozo de un pilum, una terracota indeterminada, un fósil marino y restos de frisos que podrían formar parte de una construcción.

Estos fragmentos arquitectónicos apoyarían uno de los elementos más repetidos por la historiografía que consiste en la presencia de los restos de un posible aediculum situado en la cumbre de la montaña alrededor del cual han aparecido todos los materiales arqueológicos (BRU, 1958, 162-163; BELTRAN, 1951, 247; CORELL, 1988, 140-141; GARCIA SANZ, 1990, 266, 0.2; OLIVER, 1986, 119). Ribelles escribió:

«no queda rastro alguno de las paredes o cimientos de tal Templo, y las piedras que algún día estuvieron empleadas en él, tiene la superficie exterior mohosa y acanalada. Alrededor de estas piedras se ven otros indicios nada equívocos del Templo que alli existió porque conservan todavía molduras y una de ellas es una voluta esquinada de cornisa» (RIBELLES, principios del XIX, 786).

Es cierto que en la cima sí podemos observar una concentración de piedras formando una estructura más o menos circular pero totalmente destrozada; además, desperdigados por el terreno hay fragmentos de frisos con una decoración moldurada sencilla. Sin olvidar las nueve lascas y el fragmento indeterminado con restos de enlucido (aunque al ser tan pequeños y no tener forma es difícil darles una función), los restos arquitectónicos apoyan la posible existencia de una edificación en este lugar.

\section{Fuentes antiguas y testimonios arqueológicos saguntinos relacionados con Liber y el vino}

A todos estos factores, que se encuentran en el propio yacimiento, se unen otros destacables por el hecho de vincularse al territorio saguntino y por estar relacionados con el vino y con Liber. Nos referimos a las fuentes antiguas y a los testimonios arqueológicos del área saguntina. 
Respecto a las fuentes antiguas se muestra, por un lado, el máximo desarrollo de la vid en Sagunto durante el siglo I d.C. o primera mitad del II d.C. y, por otro lado, que el vino saguntino era conocido más allá de sus límites (Juv., Sátiras. I, V, 25-30). Fronton (Front., Epistulae. I, 4, 8-13) se refiere al vino saguntino como de mala calidad comparado con el de Falerno.

Plinio el Joven (Plin., Epistulae IX, VII) en una carta a Voconio Romano, propietario de viñedos en Sagunto, pretende convencerle de las grandes ventajas que tiene plantar viñas en sus tierras.

De forma indirecta también hablan de los vinos saguntinos Marcial (Mart., Ep. I, IV, 46, 12-17; II, VIII, 6,1-4; III, XIV, 108) y Plinio (Plin., H.N. IX, XXXV, 160161). Según Marcial los vasos saguntinos están mal torneados, mal decorados y son baratos. Plinio el Viejo cita los vasos que se fabrican en Sagunto para beber vino.

Los testimonios arqueológicos, como la producción propia de ánforas vinarias, su presencia en Roma y la existencia de explotaciones de vino, demuestran la existencia de una activa producción vinícola de autoconsumo y exportadora; una estatuilla de bronce (BLECH, 1989, 81-83) aparecida en el castillo de la propia ciudad de Sagunto, un mosaico (OLCINA, 1991, 49) donde aparece Baco y una piedra posiblemente relacionada con una instalación agrícola de vino dedicada a Liber cerca de Sagunto, la relacionan con este dios:

- La presencia de este vino en Roma viene confirmada por el hallazgo allí del sello saguntino B.C. MATERNI/SACYNTO (ARANEGUI-MANTILLA, 1987, 101).

- La marca GEM aparece en las ánforas Dr. 2-4 hechas en Sagunto y en un cepo de ancla; esta abreviación de los nomina es propia de estas fechas, lo que quiere decir que existiría un negotiator saguntino en estas fechas y en este lugar relacionado con el vino (ARANEGUI, 1990, 15; ARANEGUI-MANTILLA, 101).

- Se conocen dos explotaciones vinícolas, una en la zona de El Puig (Valencia), a la cual pertenece la marca B.C. MATERNI/SACYNTO, y otra en la partida de Els Arcs en Estivella (Valencia), localizada a través de la marca $M P M$ de época augustea (ARANEGUI, 1990, 15) que fue atribuida por Revilla (REVILLA, 1995, 185-186) erróneamente a Cataluña, concretamente, a El Vilarenc (Calafell, Tarragona).

- La estatuilla de bronce era un Liber con pátera que apareció en un sacellum junto con doce esculturas más fechadas en los siglos II y I a.C. (ARANEGUI, 1991b, 80; 1992, 60; BLECH, 1989, 81-83).

- Las primeras noticias referidas al sobrepeso son del año 1917; se describen dos grandes columnas con inscripciones romanas dedicadas a Júpiter y a Baco encontradas en un campo «en el término de Sagunto a dos kilómetros a la derecha de Sagunto, con 
dirección al mar» y fechadas "en época saguntina, posterior a la destrucción de Sagunto» (AA.VV., 1917a; 1917). Hay quien pone en duda la antigüedad del hallazgo.

El sobrepeso se encontró en unos trabajos de roturación apareciendo, entre otros restos, una cabeza de Baco. Es un yacimiento identificado como villa rustica romana a $2 \mathrm{~km}$. al noreste de Puzol, en la partida de Gausa. Está desaparecida (CORELL, 1988, 138).

Descrito por Beltrán como una piedra cilíndrica tosca con dos entalladuras en los lados de $30 \mathrm{~cm}$. de profundidad, con una altura de $1,60 \mathrm{~m}$. y 1,40 m. de diámetro. No teniendo morfología de pedestal lo relaciona con una instalación agrícola de vino (BELTRAN, 1980, 238, 289). Corell la identifica como un contrapeso de prensa de aceite y sitúa la inscripción dentro de una cartela rebajada con forma de tabula ansata en la parte superior frontal. Lo fecha en el siglo I o II d.C., pero la falta de paralelos la hace insegura (CORELL, 1988, 136-138).

La primera lectura fue LIBERO=SIEPE (AA.VV., 1917). Beltrán leyó, LIBERO/ S.I.EP: Libero/S(acrvm) I EP i?. Corell interpretó esto: LIBERO/S L F P: Libero/ S(acrvm) L(vcivs) F(---) P(---). Se trataría para Corell de la fórmula sacrvm y el nombre del dedicante con las iniciales. Otros autores siguen esta misma lectura (CEBRIAN, 1993, 121; DEL HOYO, 1992, 73; GARCIA SANZ, 1990, 254-255; 1991, 190).

\section{Especialización del Culto}

Todos estos aspectos que obtenemos para época romana son muy importantes, tanto que los creemos suficientes para confirmar la relación de la Montaña Frontera con el vino y con un culto especializado a Liber Pater como dios del vino.

Ahora bien, este tipo de culto es practicado por una sociedad que hemos podido estudiar a través de las ofrendas epigráficas latinas halladas en el santuario. En ellas encontramos algunas diferencias sociales. En general, la clase aristocrática altoimperial tiene tria nomina, cargos diversos, una posición económica elevada y la fórmula de la dedicación suele ser f.c., d.d., p.c., etc.; y por las distintas formas de expresar sus votos vemos que el soporte de sus inscripciones votivas son pedestales, utilizando, principalmente, el mármol (DEL HOYO, 1988a, 305-307). En la Montaña Frontera todos los hombres libres llevan su tria nomina y conocemos a dos duumviros cuya importancia radicaba en las funciones que cumplían: nombrar y supervisar las actividades de los jueces del municipio, proponer la manumisión de esclavos públicos y la construcción y reparación de obras de infraestructura (CEBRIAN, 1993, 77); contamos con tres pedestales con inscripción, junto con otra cantidad de ellos anepigráficos (o fragmentados) y en mármol tenemos presencia, aunque escasa, de dos inscripcio- 
nes (de mármol, también, apareció parte de la mano y muñeca de una escultura de pequeño tamaño). Como fórmula votiva sí que encontramos un faciendvm cvravervnt una vez.

La clase inferior porta una onomástica propia de esclavos o libertos, no tienen cargos sociales, su posición económica es baja y la fórmula dedicatoria es votvm; los soportes de las inscripciones son aras, etc, de arenisca o caliza (DEL HOYO, 1988a, 305-307). En la Montaña Frontera hemos hablado de dos libertos, un hombre y una mujer; la mayor parte de las dedicaciones son v.s.l.m., ex voto o sólo v, sobre aras y arulas tanto epigráficas como anepigráficas, de piedra caliza dolomítica local. Se distinguen unos soportes con letras mejor labradas que en otros.

Vemos cómo estos rasgos generales sí se cumplen pero no completamente. Por ejemplo, el mármol es un material noble que implica gastos mayores y su presencia expresa una diferencia social; pero diferenciar entre pedestal o ara para encontrar distintos niveles sociales no se puede aplicar estrictamente a este lugar por ser de muy difícil acceso (además, el ara es el soporte para las inscripciones votivas más abundante en el territorio valenciano en época romana (CEBRIAN, 1993, 145). En este sentido, también, habría que explicar el pequeño tamaño de todos los soportes como un rasgo propio de este santuario. La fórmula votiva en la mayoría es un votvm y son ofrendas de hombres libres, en parte de origen servil. El mármol es muy poco abundante pero sólo su presencia ya implica disparidad social. Entonces, las diferencias anteriores creemos que sí se deben hacer notar porque, en parte, se cumplen; se trata de ciudadanos libres en su mayor parte y de pocos personajes importantes; vemos cómo este yacimiento presenta unas características propias.

Cabe añadir que se ha reflejado como una diferencia social el hecho de que aparezca mencionado el nombre de Liber Pater o no en las dedicaciones. Si lo nombra pertenece a un nivel social más alto (GARCIA SANZ, 1991, 178), o mejor, más culto.

Respecto a los libertos, en "Hispania, los libertos parecen tener un cognomen griego, o hispano de dueño latino, o son latinos liberados por un hispano, es decir, los esclavos y los libertos suelen ser extranjeros con respecto a sus dueños» (VAZQUEZ HOYS, 1981, 43). En la Montaña Frontera tenemos esto mismo: los dos libertos llevan un cognomen griego pero la liberta lo lleva latino. Por otra parte, ya que sabemos que un liberto hizo una ofrenda a Liber Pater sobre un fragmento de ara o pedestal fechado con seguridad en el siglo II d.C., deberíamos recordar que está probada la intervención de libertos en el negocio del vino en el siglo II d.C. (ARANEGUI, 1993, 142).

En todas las inscripciones legibles los dedicantes son hombres menos en dos. J. del Hoyo estimó como preponderantemente masculino el culto a Liber Pater en 
Hispania (DEL HOYO, 1992, 89). Por otra parte, se ha contabilizado que los hombres aparecen más en dedicaciones a dioses que las mujeres (VAZQUEZ HOYS, 1982-83, 137). Lo que es importante señalar es que estas dos mujeres están representadas entre los devotos.

En conclusión, la presencia en la Montaña Frontera de hombres libres, de una mujer libre, de libertos y de dos duumviros, junto con la variedad en el tipo de ofrendas (vasos cerámicos, ánforas, dolia, pedestales o aras/arulas, bloques, un fragmento escultórico, etc.), el empleo del mármol (abunda la caliza dolomítica pero el mármol está representado aunque sea en poca cantidad: dos inscripciones latinas, un fragmento de mano esculpida, tres fragmentos sin forma y una posible ara o arula) y el número igualado de ofrendas epigráficas y anepigráficas (sin olvidar que el gran deterioro de las piedras puede haber provocado que la parte de la pieza donde lleva las letras se haya perdido), refleja un culto popular campesino llevado a cabo por gentes de distintas clases sociales, que pudieran estar distanciados por la forma de expresar sus votos pero que están unidos por un mismo culto que conocen y aceptan.

\section{Asimilación del Culto}

Ahora bien, sabiendo que nos encontramos ante una sociedad compleja que ofrece sus votos a un dios protector de la viña a partir de la romanización, nos faltaría resolver el carácter que tuvo este lugar en época ibérica, las características de la divinidad si la hubo y su evolución hacia el dios que nos encontramos en el período romano. Esto nos introduce en una cuestión que está relacionada con el fenómeno del sincretismo.

Esta idea sobre el fenómeno sincrético en la Montaña Frontera fue expuesta por primera vez por M. Tarradell (TARRADELL, 1979, 35-37, 44-45) que ubicaba en el mundo ibérico el origen de estos lugares sagrados situados en lugares altos entre ellos éste, produciéndose sincretismos que lo llevaban hasta época romana. Bruhl (BRUHL, 1958, 121) en su obra sobre Liber Pater habla ya de un santuario descubierto por M. Maiuri situado en un lugar alto dedicado a él en la colina de San Abbondio en Pompeya, que siguió utilizándose bajo la dominación romana y que consideró que no sería el único santuario en esa zona ya que era muy rica en viñedos.

Los indicios que revelan este proceso le parecían difíciles de determinar porque tan sólo conservan la mayor parte de ellos restos romanos, sobre todo inscripciones sagradas, pero nunca vestigios más antiguos como cerámica o exvotos en forma de figurilla. Estudió los posibles santuarios en altura del territorio catalán, añadiendo el de Sta. Bárbara (VICENT, 1977; 1979) en la Vilavella de Nules en Castellón y la Montaña Fronte- 
ra en el término de Sagunto en Valencia. Los incluía en este grupo por los indicios arqueológicos y este último por el culto a una divinidad agrícola anterior (TARRADELL, 1979, 35-37, 44-45) (tiene conocimiento de inscripciones romanas, de un pequeño edificio y de cerámica ibérica y romana). Pero además de esto, ahora se conocen numerosos restos cerámicos ibéricos junto con un grupo uniforme de inscripciones ibéricas sobre soportes de tipología romana datadas en el siglo I a.C. (pedestales, aras y arulas) y se tiene conocimiento de figurillas de bronce aparecidas en el yacimiento, aunque esto último no se puede confirmar al estar todas en paradero desconocido; es decir, aquí sí que tenemos los restos que echa en falta este investigador en este tipo de santuarios, lo que apoyaría con más fuerza su proposición.

En total, los signos ibéricos aparecen en treinta y nueve fragmentos de piedra, en dos casos sobre cerámicas que no conservan su forma original aunque sí se pueden advertir unos rasgos generales. La mitad de las piezas portan uno o dos agujeros en sus superficies (siempre relacionados para fijar una estatuilla votiva, bien la imagen de la divinidad o bien la del oferente) y cuatro llevan una decoración arquitectónica muy deteriorada (decoración moldurada y volutas). La otra mitad no presenta nada de esto; son fragmentos mucho más deteriorados y, quizá por ello, no conservan los rasgos que definen las otras piezas. El empleo de pedestales nos lleva a una cronología augustea y las arulas implican la celebración de un ritual propio de la romanización en donde estos objetos se debían separar del suelo para ser propicios a los dioses.

Respecto a lo que dicen estas inscripciones parece algo reconocido que Bokon pudiera ser el nombre de una divinidad indígena que era adorada en este lugar. Esta divinidad indígena, fuera cual fuera su nombre, tendría un carácter agrícola ejerciendo gran influjo en toda el área circundante (SILGO-FLETCHER, 1987, 60) y se asimilaría a Liber Pater; otros investigadores lo interpretan como un antropónimo (UNTERMANN, 1990, 422). Se lee en dos inscripciones:

1- Lectura (FLETCHER-SILGO, 1987, 45-53):

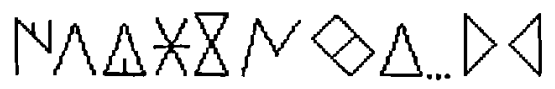

Restitución: Ildubokontedu[-]ar (FLETCHER-SILGO, 1987, 45-53) o iltubokontetu* ${ }^{*}$ ) ar o iltutakon- (UNTERMANN, 1990, 422).

2- Lectura:

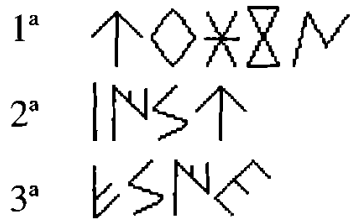

Restitución: ...]u-rv-bo-ko-n[...; ba-i-s-u[...; ...]e-s-i-te[... (Lám. 7, fig. 1). 
Junto a un dios, se han determinado cinco nombres de dedicantes: Intebeles (Lám. 7, fig. 2), Baisu, Baiser, Koite (este está incompleto) y otro con varias interpretaciones: (Ai)ebeles, ebeles, isebel (o ka), o (ne)eten(cu). Otros términos a destacar que aparecen una sola vez son Baiser, una palabra muy común en la zona saguntina; Iltu, un formador de topónimos y -ar, un sufijo que señala que la ofrenda era propiedad del dios. Destacados porque son los únicos que se les puede sacar un significado aunque no aporten información concreta sobre lo que quieren decir estas inscripciones. A estos nombres se suma la inscripción ibérica sobre el ala de un kalathos (OLIVER, $1986,121)$ que se ha interpretado como un nombre personal, posiblemente, el del dedicante (se han dado varias lecturas: [---]ULTIBAISERTEKAUKOR[---], [--]ULTIBAISERTEEUKOR[---] O [---ULTIBAISERTEKAUKOKU[---] (UNTERMANN, 1990, 425, F.11.32; VELAZA, 1991, 173, 831; SILGO, 1992, 356, XXXIV; 1994, 59,103, 132, 250).

Como se puede comprobar, estamos ante un santuario donde debía existir una divinidad ibérica, a la cual se le rinde culto a través de unas ofrendas votivas durante la romanización, y es seguro que a partir del siglo I d.C. se adora a un dios romano por medio de inscripciones latinas sobre el mismo tipo de soporte.

Durante la romanización vemos, a través de las ofrendas epigráficas, que la asimilación de una divinidad a otra parece producirse sin resistencia alguna; desde esta fecha contamos con las ibéricas (sin olvidar la inscripción sobre el ala del kalathos ya mencionado fechada en el siglo II a.C., que haría más antigua la cronología para el período ibérico) y a partir de este momento se datan ya las ofrendas epigráficas latinas, que proliferan durante el siglo I d.C., sobre todo, y el siglo II d.C., y todos los demás materiales de carácter votivo.

La continuidad cronológica de las inscripciones puede llevar a pensar en una continuidad del culto del dios. Desde luego que no va a ser el mismo pero, como dice $M^{2}$.I. Portela (PORTELA, 1984, 156; CEBRIAN, 1993, 117), para que un culto romano arraigue con fuerza tiene que ser en los lugares donde los cultos indígenas sean semejantes a aquél que se quiere implantar porque resulta más fácil asimilarlos e, incluso, substituirlos. En la Montaña Frontera estaríamos ante algo similar. Podríamos hablar de un fenómeno de sincretismo en donde la divinidad ibérica indígena sería reemplazada, con el tiempo, por Liber Pater; y si el carácter de éste es el del dios del vino, el de la divinidad local anterior estaría relacionado como mínimo, siguiendo la opinión de Portella, con la tierra y su capacidad fecundadora. 


\section{Valoración Final}

Así pues, recopilando las líneas precedentes, concluimos que la identidad de la divinidad indígena anterior se debe buscar, principalmente, en Liber Pater, que sabemos fue adorado en este santuario pero sin olvidar los rasgos propios de su entorno. La continuidad cronológica en las ofrendas epigráficas, junto con el carácter del territorio saguntino como una zona agrícola y la situación destacada del santuario en lo alto de una montaña dominando todo el territorio, además de considerar a Liber Pater como dios protector del viñedo saguntino, lleva a interpretar que allí se adoró a una divinidad relacionada con la fecundidad de los campos. A esto cabe añadir que, como dios concreto que es, se irá sincretizando en otro dios concreto, Liber Pater, cuya personalidad estaría relacionada, igualmente, con una actividad fecundadora. Ahora bien, Liber Pater no se impondría como deidad del vino en poco tiempo sino que, probablemente, primero sería adorado como la anterior divinidad indígena y, con el auge del cultivo de la vid en este territorio, es decir, conforme se iban perfilando unas necesidades concretas, fue haciéndose más específico su carácter; esto explicaría su fácil asimilación con la deidad anterior y, en consecuencia, que fuera un culto muy arraigado entre los pobladores saguntinos.

\section{BIBLIOGRAFIA}

AA.VV. (15-II-1917): «Hallazgo arqueológico». Diario de Valencia.

a-: (15-II-1917): «Descubrimiento arqueológico en término de Sagunto». Las Provincias.

ALFÖLDY, G. (1977): «Los Baebii de Saguntum». TV 56, 35.

- : (1981): «Ein Corpus der römischen Inscriften aus Saguntum und Umgebung». AEA 54, 117-140.

- : (1995): «Tituli sacri prope sanctuarium Liberi patris in Muntanya Frontera constructum reperti». CIL 2, Fasc. I, 126-130.

ARANEGUI, C. (1990): «Arqueología del vino. Sagunto». Braçal 3, 12-16.

a- : (1991): «El vino de Saguntum». Saguntum y el Mar, Valencia, 49-52.

b- : (1991): «Un templo republicano en el centro cívico saguntino». Templos romanos de Hispania, Cuadernos de Arquitectura Romana I, 67-82.

- : (1992): «Evolución del área cívica saguntina», JRA 5, 56-68.

- : (1993): «Datos para el conocimiento de Sagunto en el siglo II». Estudios dedica- 
dos a J.M. Recasens, La cité et la communauté civique en Hispania aux III et II siècles ap. J.C., 139-146.

-: (1994): «Iberica Sacra Loca. Entre el Cabo de la Nao, Cartagena y el Cerro de los Santos». REIb 1, 115-138.

-: (1996) (coord.): Els romans a les terres valencianes. Politècnica 61, Valencia .

ARANEGUI, C.; MANTILLA, A. (1987): «La producción de ánforas Dr. 2-4 de Sagunto». El vi a l'antiguitat. Economia, producció i comerç al Mediterrani occidental, $100-104$.

ARCE, J. (1986): «Dionysus-Bacchus in Roman Spain». BCH 14, 168-174.

BELTRAN, F. (1980): «Epigrafía latina de Saguntum y su territorium». TV 67, 154, $254-260,238$ y 388.

BELTRAN, P. (1951): «Hallazgos en Sagunto». AEA 24, 246-247.

BLECH, M. (1989): «Republikanische Bronzestatuetten aus Sagunt». Homenatge A.Chabret, 45-91.

BOUCHER, S. (1988): «Dionysos/Bacchus (in peripheria occidentali)». Lexicon iconographicum mythologiae classicae IV-1, 908-923.

BRU, S. (1958): «Arqueología Saguntina». A.P.L. VIII, 162-163, 169-171.

BRUHL, M. (1953): Liber Pater. Origine et expansion du culte dionisiaque a Rome et dans le monde romain. Paris.

CEBRIAN, R. (1993): La Sociedad Romana en el País Valenciano a través de la Epigrafía. Tesis de Licenciatura, Universidad de Valencia.

CHINER, P. (1990): La decoración arquitectónica de Saguntum. Valencia.

CORELL, J. (1988): «El culto a Liber Pater en el sur del Conventus Tarraconensis según la epigrafía». Religio Deorum: Actas del Coloquio Internacional de Epigrafía. Culto y Sociedad en Occidente, 125-143.

DEL HOYO, J. (1988): «Liber Pater dans l'épigraphie hispanique: relations entre la viticulture et le culte du dieu». Caesarodonum 24, 99-122.

a (1988): «Relación culto-estrato social en la Hispania Romana». Religio Deorum: Actas del Coloquio Internacional de Epigrafía. Culto y Sociedad en Occidente, 303-308.

- : (1992): «Revisión de los estudios de Liber Pater en la epigrafía hispana». Mélanges de la Casa de Velázquez, XXVIII (1), 65-92. 
FLETCHER, D. Y SILGO, L. (1987): «Repertorio de inscripciones ibéricas procedentes de Sagunto (Valencia)». Arse 22, 45-55.

GARCIA SANZ, O. (1990): Baco en Hispania. Economía y Religión, a través de las fuentes epigráficas, arqueológicas y literarias. Tesis Doctoral, Universidad Complutense de Madrid.

- : (1991): «Liber Pater epigráfico en Hispania: Textos y contexto religioso». Espacio, Tiempo y Forma, Serie II, $\mathrm{H}^{\mathrm{a}}$ Antigua, t. IV, 171-198.

- : (1991-92): «Algunos apuntes sobre Baco en Hispania». Anas 4-5, 105-114.

GRIMAL, P. (1984): «Liber». Diccionario de Mitología Griega y Romana.

HATT, J.J. (1991): «Le Sucellus-Silvain-Liber Pater de Javols (Lozère): Signification

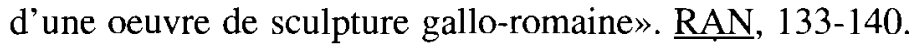

MANGAS, J. (1978): «Religión y cultura». Historia de España Antigua II, Hispania Romana, Madrid.

- : (1990): «Valencia». HEp 2, 202-209.

- : (1993): «Valencia». HEp 3, 150-158.

MAU, A. (1979): «Dolium». Der kleine Pauly, Baud V, 1, 1284-1286.

NICOLAU, M. ${ }^{a}$ R.: (1997): El santuario iberorromano de la Montaña Frontera (Sagunto, Valencia). Tesis de Licenciatura, Universidad de Valencia.

- (e. p.): «La Montaña Frontera: Historia de la Investigación». $2^{\circ}$ Congrés d'Estudis sobre el Camp de Morvedre.

OLCINA, M. (1991): «El descubrimiento del mosaico de Baco en Sagunto». Historiografía de la Arqueología y de la Historia Antigua de España, siglos XVII-XX, 49-55.

OLIVER, A. (1986): «Grafitos ibéricos procedentes de la Montanya Frontera (Sagunto)». Saguntum 20, 117-122.

PORTELA, M ${ }^{\mathrm{a}}$.I. (1984): «Los dioses Lares en la Hispania romana». Lucentum III, 153-180.

RAMALLO, S.F.: «La monumentalización de los santuarios ibéricos en época tardorepublicana». Ostraka 2, 117-144.

REDONDO, J.A. (1987-1988): «Reflexiones sobre epigrafía de Liber». Norba 8-9, 43-53.

- : (1988): «Algunas consideraciones acerca del Liber Pater venerado en la Alta Extremadura». I Coloquio de Historia Antigua de Andalucía, 237-247. 
REVILLA, V. (1995): Producción cerámica, viticultura y propiedad rural en la Hispania Tarraconense (I a.C.- II d.C.). Barcelona.

RIBELLES, B. (principios del XIX): «Colección de lápidas». Archivo del Real Convento de Predicadores de Valencia MS. 17, 214, 376-380.

a- : (principios del XIX): "Varia». Archivo del Real Convento de Predicadores de Valencia MS. 81, 751-755, 767-771, 779-784 y 785-788.

ROCA, F. (1988): Epigrafía latina e ibérica saguntina, Arse 23, 79-86.

ROSE, H.J. (1976): «Liber Pater». The Oxford Classical Dictionary, 607.

SILGO, L. (1989): «Tres inscripciones ibéricas». Arse 24, 17-20.

- : (1992): Textos ibéricos valencianos (Contestania, Edetania, Ilercavonia). Tesis Doctoral, Universidad de Valencia.

- : (1994): «Léxico ibérico». RACV, Sección de Estudios Ibéricos, Estudios de lenguas y epigrafía antiguas- E.L.E.A., Valencia.

SILGO, L. (1987); FLETCHER, D.: «Dos nuevos textos ibéricos saguntinos». Arse $22,57-62$.

TARRADELL, M. (1979): «Santuaris ibèrics i ibero-romans a llocs alts». Memòria de l'Institut d'Arqueología i Prehistòria de la Universidad de Barcelona, 35-45.

TOUTAIN, J. (1900): «Liber Pater». Dictionnaire des Antiquités grecques et romaines III-2, 1189-1191.

UNTERMANN, J. (1990): Monumenta Linguarum Hispanicarum III, Die iberischen Inschriften aus Spanien, Wiesbaden.

VAZQUEZ HOYS, A.M. (1981): "Algunas consideraciones sobre cultos locales en 1a Hispania romana». Memoria de Historia Antigua V, 41-50.

- : (1982): La Religión romana en Hispania. Fuentes epigráficas, arqueológicas y numismáticas I-II, Tesis Doctoral, Universidad Complutense de Madrid.

- : (1982-83): «La mujer en la epigrafía religiosa hispanorromana». Cuadernos de Prehistoria y Arqueología 9-10, 17-150.

VELAZA, J. (1991): «Léxico de inscripciones ibéricas (1976-1989)». Aurea Saecula $4,42,75$ y 174.

VICENT, J.A. (1977): La Vilavella, estudio histórico-arqueológico, Valencia.

- : (1979): «Excavacions al santuari Hispano-romà de Santa Bàrbara». CPAC 6, 181-221. 


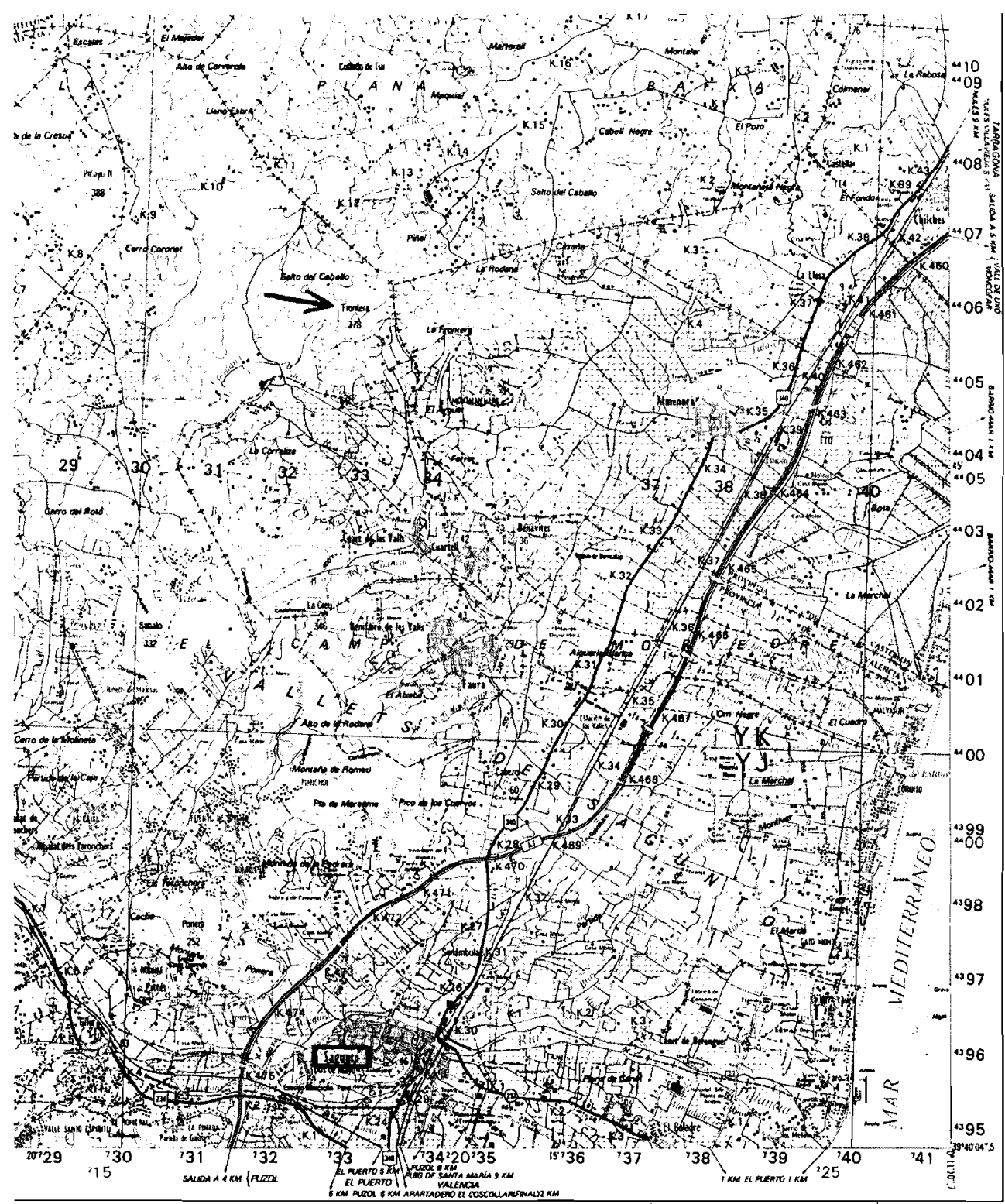

Lám. 1: Situación geográfica de la Montaña Frontera (mapa del S.G.E.) 
$M^{a}$ ROSARIO NICOLAU VIVES
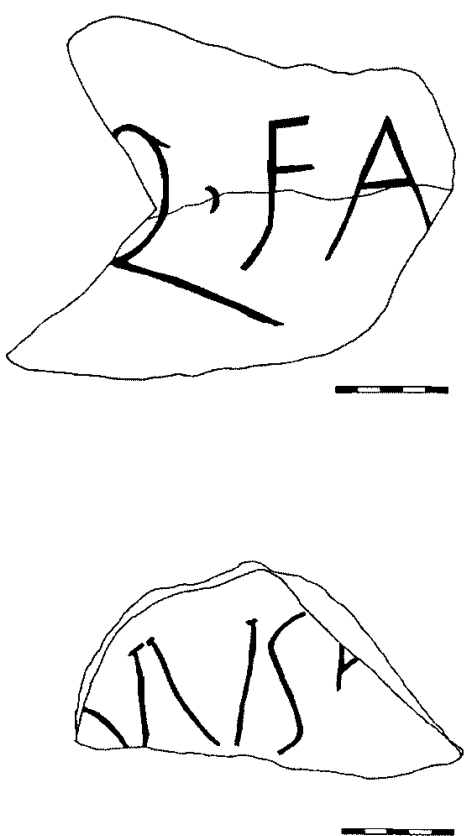

$n^{0} 2$

$n^{9} 1$

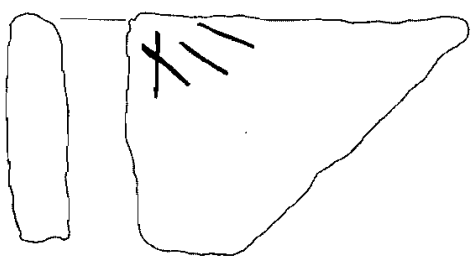

$n^{9} 3$
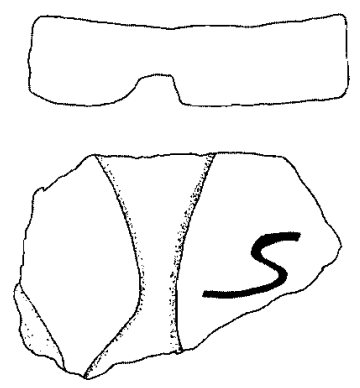

$n^{9} 4$

Lám. 2: Marca de dolia, nōs. 1 y 2

Lám. 3: Marca de dolia, nํㅗs. 3 y 4

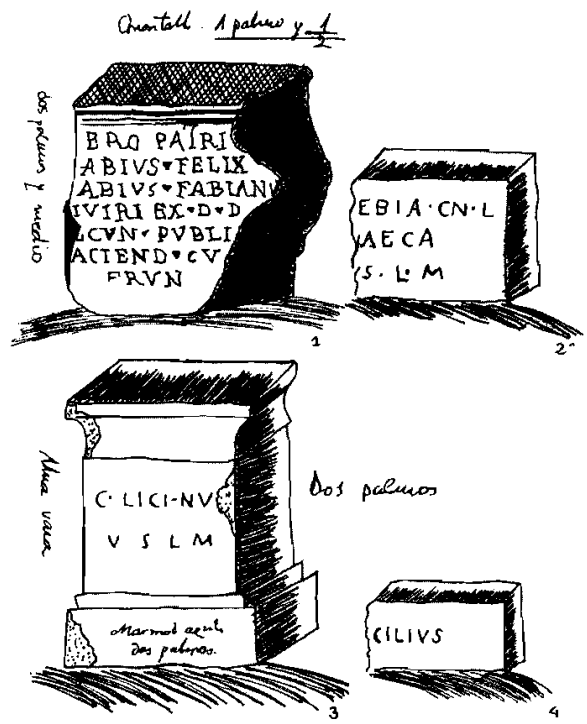

Lám. 4: Inscripciones recogidas por

Ribelles. La no 4 es la más antigua.

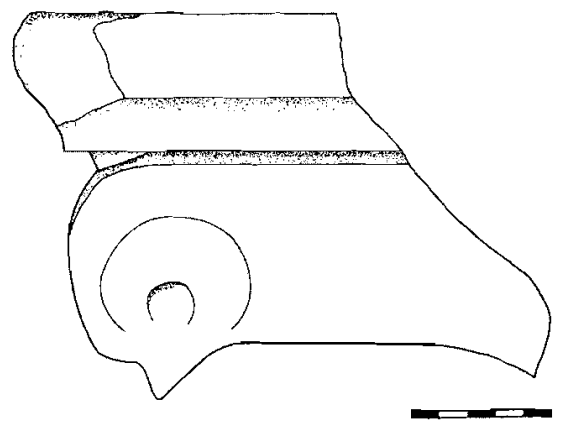

Lám. 5: Sello de T.S.G. y fragmento de capitel jónico

48

--- Grupo de investigación P.A.I. HUM 236 | http://www.arqueocordoba.com/publ/anales.htm --- 

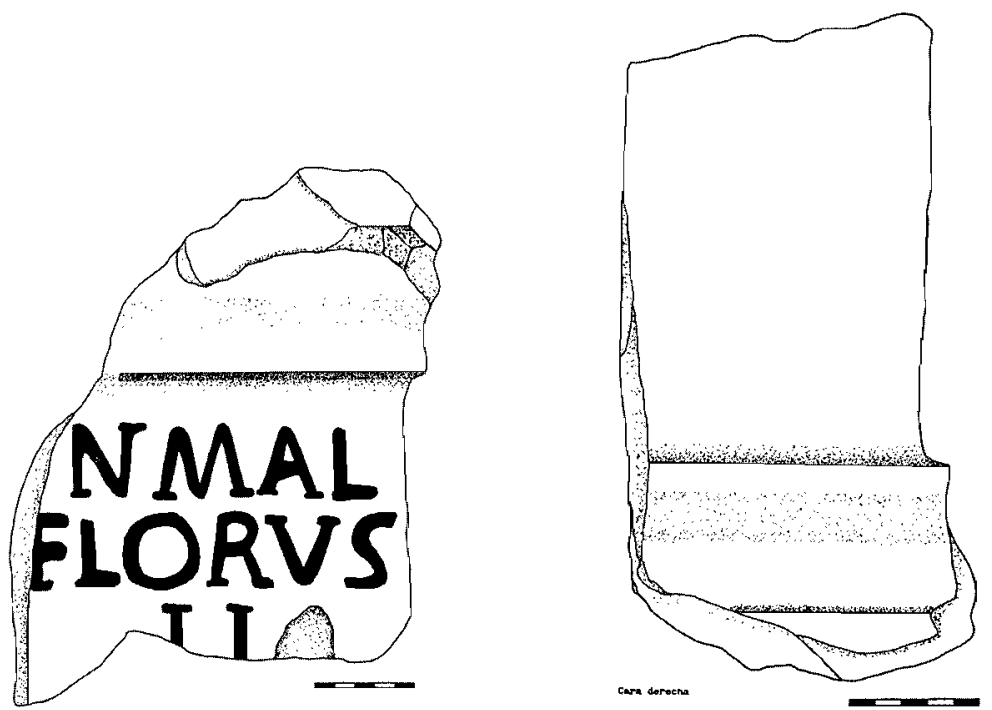

Lám. 6: Fragmento de inscripción latina con mejor ejecución.
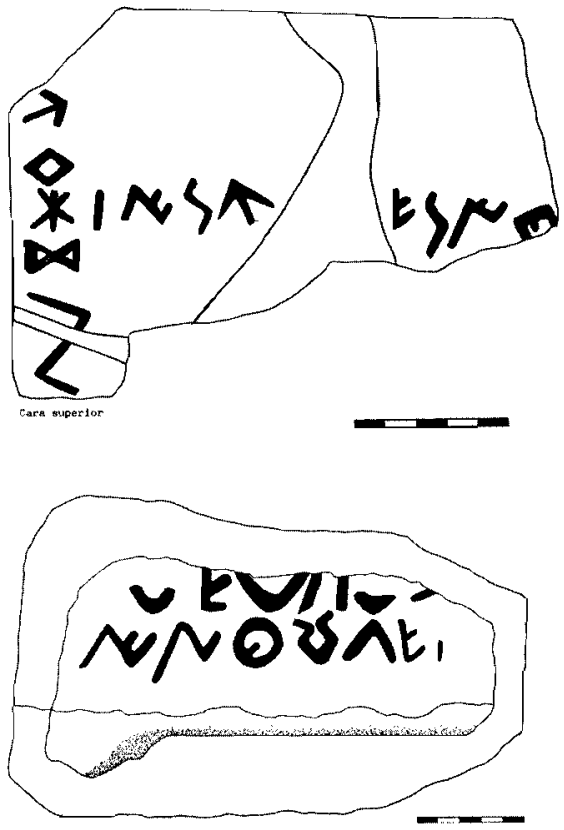

Lám. 7: Fragmento de inscripción ibérica donde se lee el término Bokon y fragmento de inscripción ibérica donde se lee el término Intebeles. 